\title{
MANUAL THERAPY EDUCATION. DOES E-LEARNING HAVE A PLACE?
}

\section{Liz Holey and Dr Paul Bowley}

$\underline{\text { Introduction }}$

The practical, psychomotor skills integral to manual therapy require considerable development to ensure a practitioner is competent to practise safely. Traditionally, this has been learned through a cycle of observed demonstration, practice and teacher feedback where the student's attempts are observed and commented upon, followed by a refinement of practice, of tasks designed with a gradual increase in complexity. This process is both effective and efficient for the learner.

To enable autonomous professional clinical practice these skills must be embedded within a framework of assessment, diagnosis, clinical decisionmaking, evaluation and reflection. This ensures that an individual needsbased assessment package is prescribed and delivered effectively over a course of time (Holey and Cook, 2003). The reflective practitioner (Schon, 1987 ) this produces is able to be self-critical and maintain competence over a working life. Experience has shown that learning the psychomotor skills and intellectual framework in an integrated way is the most effective. This has led to an assumption that e-learning, therefore, is an inappropriate learning and teaching strategy for manual therapy, but this paper argues that it has a place in supporting and enhancing the learning of the manipulative therapies. 
$\underline{\text { Intellectual Skills }}$

The expert becomes distinct from the novice by his/her ability to make complex clinical decisions through a sophisticated process of clinical reasoning. Progression from novice to expert is developed through clinical experience. It is thought that by experiencing a wide range of patients with their varied clinical presentations and differing responses to treatment enable the expert to recognise patterns and thus make more accurate clinical decisions, more quickly (Jones and Rivett, 2004).

The integration of the underpinning theory and its use to inform problemsolving, decision-making and clinical reasoning can be learned through the exploration of case studies. These options can be undertaken on-line, without direct contact with tutor or peers and lone learning can be supported by explanations, examples and anecdotes being provided in a written or diagrammatic form on an electronic learning platform. There is a danger, however, that independent learning from written material may encourage a passive learning style. The passivity involved in learning from written material must, therefore, be supplemented by an interaction with the material and an active engagement with decision-making.

\section{Psychomotor Skill Acquisition}

A student of manual therapy needs to experience the feel of normal tissues and joints and the way they respond to manipulative techniques. They then 
need to experience the same in a variety of patients with different abnormalities. Only then will the student understand, in a field suffering from a paucity of objective measures of tissue response, when these responses to treatment are 'normal', desirable and related to symptoms. It is accepted that there is no substitute for real palpation and handling of joints and tissues, and communicating and responding to human individuals. High level technological learning objects can, however, supplement this practice in actuality and prepare students to practise on humans.

\section{The possibilities of e-learning}

A virtual learning environment can be created in which a total learning experience can be enjoyed. Activities within this environment can be used to enrich learning in novel ways. Sensitive selection of learning activities and experiences at appropriate points, and skilful linkage of activity to learning outcomes can take the learner through a journey of discovery, achievement, feedback and fun. The journey can be taken in the virtual company of others, via electronic communication. Sophistication varies from the reading of material, watching video clips and PowerPoint presentations, to watching animations and engaging in tests, quizzes, interactive case-based exercises and electronic discussions.

\section{Definitions of E-Learning}

Definitions of e-learning proliferate, but for the purposes of this discussion e- 
learning can be defined as technology-based instruction delivered by means of a computer network (Welsh et al., 2003; Zhang et al., 2004), most commonly nowadays via the World Wide Web. Two distinct types of elearning have been identified (Welsh et al., 2003): synchronous, where all students access learning materials at the same time; and asynchronous, where pre-prepared materials are accessed by students at any time.

Currently, the most popular forms of asynchronous e-learning are blogs, wikis and podcasts, which will be the initial subject of discussion. Technologies that are more obviously applicable to the field of manual therapy, namely simulations and devices that provide haptic feedback will then be explored. Whilst adding fun can be an added benefit, it is important that the on-line teacher is able to select the tools which are appropriate to the learning outcomes and that 'gimmicks' are avoided.

\section{$\underline{\text { Really Simple Syndication (RSS) }}$}

RSS is a means of disseminating content from frequently updated Web sites through documents known as 'feeds', and is connected with blogs, wikis and podcasts. RSS feeds (composed of XML - Extensible Markup Language) can be gathered from Web sites through the use of programs known as 'readers' or 'aggregators'. Users direct such programs to visit Web sites of interest to pick up the latest feeds, which may contain listings of news headlines or podcasts, for example. In this way, content can be collected conveniently 
from a variety of sources without the user having to visit a number of Web sites.

\section{Blogs}

The term 'blog' is a contraction of 'Web log', and is thought to have come into use in 1999 (Williams and Jacobs, 2004). The blog in its most basic form is an online journal with entries displayed in reverse chronological order. Entries are mostly textual, but can contain links to other Web sites and multimedia. Blogs also generate RSS feeds.

An important feature of the blog is that readers can post comments to each entry, which lends the blog a collaborative, conversational style. As an educational tool, therefore, Blogs provide a means of sharing knowledge and a forum for debate on any conceivable topic. In Williams and Jacobs' (2004) study of an MBA blog at Brisbane Graduate School of Business, most students felt that the blog 'increased the level of meaningful intellectual exchange' amongst peers.

Glogoff (2005) sees the addition of comments to blog entries as a useful means of giving immediate feedback to students on their blog entries, which in turn can be an aid to directed learning and guided discovery.

$\underline{\text { Wikis }}$ 
The word 'wiki' comes from the Hawaiian meaning 'swift' or 'to hurry' (Boulos et al., 2006). The most well-known example of the wiki is Wikipedia - The Free Encyclopedia. The wiki is a collection of Web pages, the content of which can be modified by anyone with relative ease through a Web browser. Most wikis maintain archived copies of their Web pages, allowing the evolution of each page to be monitored. Like blogs, wikis can also generate RSS feeds for the dissemination of the latest updates. The open editing feature of the wiki lends itself to a number of uses in an e-learning context: collaborative writing projects, group problem-solving projects, the creation of shared information sources and the provision of customised electronic portfolios have been identified (Ferris and Wilder, 2006).

The same feature has led to the accuracy of the content of wikis being viewed with some suspicion. However, Boulos et al. (2006) posit that the collaborative editing process should lead to a 'survival of the fittest' content through a kind of natural selection. Nevertheless, wikis require careful monitoring to ensure accuracy of content.

\section{Podcasts}

Cebeci and Tekdal (2006) define podcasting as the Web syndication (e.g. through RSS) of audio content (e.g. voice or music recordings) to mobile devices (e.g. mobile phones or MP3 players). In fact, the audio content of a podcast can be played on virtually any personal computer. 
The ease with which the podcast can be created and distributed is one of its key features. An inexpensive microphone, a personal computer and some free, open-source recording software will suffice (Tavales and Skevoulis, 2006).

In an educational context, podcasts can be used to distribute recordings of lectures and supplementary materials, making them a convenient reference resource that can be accessed regardless of time and, given the appropriate player, location. They also offer students the option of learning through listening, which some students may prefer and others, such as the visually challenged, may require (Cebeci and Tekdal, 2006).

$\underline{\text { Simulations }}$

Simulations can range from Web-based applications containing text, graphics and multimedia (sound, video) to three-dimensional (3D) model environments.

An example of the former type is Web-SP, a Web-based simulated patient system (Brutlag et al., 2006). Cases are customised and can include patient interviews, physical examinations and laboratory tests. Students can also make diagnoses and receive feedback on them.

Of the latter type is the 3D virtual radiography application developed at the University of Teesside. This application allows students to position a virtual patient and X-ray tube independently in a number of scenarios and see the 
effects of those manipulations on the resulting X-ray exposure. The program has so far proved invaluable in training students of diagnostic radiography in a radiation-free environment.

Also of the latter type, this time incorporating a haptic feedback device, is the Virtual Haptic Back project (Williams et al., 2003). This application features a virtual 3D model of the human back and the Personal Haptic Interface Mechanism (PHANTOM). The PHANToM is a mechanical device through which the student can apply forces to the virtual back and receive a realistic sensation of the resistance to those forces, as if he or she were palpating a human back.

\section{Evidence-based Learning and Teaching}

Just as our clinical practice should be evidence-based, so should our teaching. A detailed critical review of the literature is beyond the scope of this paper but it is recognised that evidence for the effectiveness of e-learning remains scanty. It has, however, been found that e-learning is suitable for use in Higher Education (Koskela et al (2005). To reduce learner isolation, a buddy system can be beneficial (Pallof and Pratt, 1999). Unsurprisingly, students with high computer confidence appear best suited to e-learning (Lain and Aston, 2004). Graff (2006) found that student performance is improved by a sense of on-line community, and engagement with assessment. Lake 
(2001) has identified that student satisfaction may decrease with the need to take learner responsibility.

\section{Blended Learning}

Our experience of delivering e-learning at the University of Teesside, UK has shown that the blended learning approach is particularly appropriate and effective. This is where e-learning is supplemented with periods of face-toface contact and this is essential where manual therapy skills must be learned safely. This must be woven into a total, logical learning experience where the context is set at induction, information is given and shared and the learning experience is structured via the electronic platform. Learners are most likely to complete the course if an on-line community is built. Assessment and testing can be electronic and include a practical assessment of manual skills which is commonly combined with a viva element to test clinical reasoning and justification of intervention. A component of assessment which is essential for learning is feedback on performance and achievement.

To enhance the quality of the electronic learning platform, a managed learning environment can be used. This is where the electronic delivery of materials is staged; for example, access is not given to new material until a quiz has been completed. This provides structure to learning, avoiding overwhelming the student by the volume of material required for completion of a whole module. It also enables close monitoring of student engagement, and can provide feedback through on-line tests and quizzes, which the student is 
motivated to complete so they can access more material and obtain formative feedback.

\section{$\underline{\text { Conclusion }}$}

E-learning can be useful to students. It can be effective in the learning and teaching of manual therapy if a blended learning approach is used.

Engagement is more effectively sustained through the provision of a sense of student community via inter-student electronic interaction and practical workshops. The enjoyment and quality of e-learning is enhanced by a high level of student engagement and the use of a managed learning environment to structure learning.

\section{$\underline{\text { References }}$}

Boulos, M. N. K., Maramba, I. and Wheeler, S. 2006 Wikis, blogs and podcasts: a new generation of Web-based tools for virtual collaborative practice and education, BMC Medical Education 2006; (6): 41

Brutlag, P., Youngblood, P., Ekorn, E., Zary, N., Fors, U., Dev, P. and Gesundheit, N. Case-Ex: Examining the Applicability of Web-based Simulated Patients for Assessment in Medical Education. In T. Reeves and S. Yamashita (Eds.), Proceedings of World Conference on E-Learning in Corporate, Government, Healthcare, and Higher Education 2006 pp18691870 
Cebeci, Z. and Tekdal, M. Using Podcasts as Audio Learning Objects, Interdisciplinary Journal of Knowledge and Learning Objects 2006; (2): 47-57

Ferris, S. and Wilder, H. 2006 Uses and Potentials of Wikis in the Classroom, Innovate 2006; (2): 5

Glogoff, S. Instructional blogging: Promoting interactivity, student-centered learning, and peer input Innovate 2005; (1): 5

Graff M 2006 The Importance of On-Line Community in Student Performance Electronic Journal of e-Learning 2006; 4 (2): 127-132

Holey EA, Cook EM Evidence-based Therapeutic Massage Churchill Livingstone, Edinburgh; 2003 ch 6: p99

Jones MA and Rivett DA, Clinical Reasoning $\square$ for Manual Therapists (first ed.), Butterworth Heinemann; 2004

Koskela M, Kitti P, Vilpola I, Tervenoven J Suitability of a Virtual Learning Environment for Higher Education Electronic Journal of e-Learning 2005; 3 (1): $21-30$.

Lain D, Aston J Literature Review of Evidence on e-Learning in the Workplace, Institute of Employment Studies, UK 2004 
Lake D Student Performance and Perceptions of a lecture-based Course Compared with the Same Course Utilizing Group Discussion. Phys Ther 2001; 81 (3): 896-902

Palloff R, Pratt K Building learning Communities in Cyberspace. JosseyBass, San Francisco; 1999

Schon D Educating the Reflective Practitioner Jossey Bass, San Francisco 1987

Tavales, S. and Skevoulis, S. Podcasts: Changing the Face of e-Learning. http://ww1.ucmss.com/books/LFS/CSREA2006/SER4351.pdf. 2006 Accessed $31 / 08 / 08$

Welsh, E. T., Wanberg, C. R., Brown, K. G. and Simmering, M. J. E-learning: emerging uses, empirical results and future directions, International Journal of Training and Development, 2003; 7(4): 245-258.

Williams, J. B. and Jacobs, J. Exploring the use of blogs as learning spaces in the higher education sector, Australasian Journal of Educational Technology, 2004; 20 (2): 232-247.

Williams II, R. L., Srivastava, M., Conatser Jr., R. R. and Howell, J. N. The Virtual Haptic Back Project, Proceedings of the 2003 Image Society Conference, Scottsdale, AZ, July 2003; 14-18.

Zhang, D., Zhao, J. L., Zhou, L. and Nunamaker Jr., J. F. Can E-learning 
Replace Classroom Learning?, Communications of the ACM, 2004; 47 (5): 74-79. 